\title{
Lactotrophs: The new and major source for VEGF secretion and the influence of ECM on rat pituitary function in vitro
}

\author{
JOACHIM ALFER $^{1,2}$, JOSEPH NEULEN ${ }^{2}$ and ANDREAS GAUMANN ${ }^{1}$ \\ ${ }^{1}$ Department of Pathology Kaufbeuren-Ravensburg, D-88212 Ravensburg; ${ }^{2}$ Department of Gynecological Endocrinology \\ and Reproductive Medicine, RWTH University of Aachen, School of Medicine, D-52057 Aachen, Germany
}

Received December 1, 2014; Accepted February 5, 2015

DOI: $10.3892 /$ or.2015.3851

\begin{abstract}
Vascular endothelial growth factor (VEGF) plays a pivotal role in pituitary endocrine function by influencing fenestration and blood vessel growth. Folliculostellate (FS) cells, which represent only a small number of pituitary cells, are recognized to produce VEGF. Tissue sections and primary pituitary cell cultures from rat pituitary glands were performed to co-localize VEGF and pituitary lactotrophs, which represents nearly $50 \%$ of all pituitary cells, by immunofluorescence. VEGF is co-localized with prolactin-producing cells in vivo and in vitro. FS cells are present infrequently in vivo (1.6\%) and in vitro $(2.4 \%)$. Culture supernatants were analyzed for the presence of VEGF by ELISA. VEGF levels are always significantly lower in supernatants from the cells that are seeded on Matrigel extracellular matrix (ECM) compared to the cells grown on plastic. Lower VEGF concentrations in supernatants from the pituitary cells cultured on ECM may reflect a more adequate cell environment compared to culture on plastic. These results demonstrate for the first time, that VEGF is expressed by lactotrophs, which outnumber FS cells. These results are of potential clinical relevance especially in oncology for the interpretation of studies investigating anti-angiogenic treatment of pituitary tumors.
\end{abstract}

\section{Introduction}

Folliculostellate (FS) cells are the first cell type in which vascular endothelial growth factor (VEGF) production was detected. Until now, FS are believed to be the only cell population within the pituitary gland to produce VEGF $(1,2)$. S-100 is a reliable marker for FS cells (3). Vankelecom et al (4) described that $\sim 7.5 \%$ of cultured mouse pituitary cells were stained for the presence of S-100. It has been suggested that FS cells perform several supportive functions. They are involved in the regulation of phagocytosis (5), and produce various growth

Correspondence to: Dr Joachim Alfer, Department of Pathology Kaufbeuren-Ravensburg, Elisabethenstrasse 19, D-88212 Ravensburg, Germany

E-mail: joachim.alfer@pathologie-ravensburg.de

Key words: pituitary, lactotrophs, folliculostellate cells, VEGF, cell culture, extracellular matrix factors $(6,7)$ and cytokines $(4,8)$. Recent studies suggest that they represent pluripotent adult stem cells (9). In situ hybridization has demonstrated homogeneous signals of VEGF mRNA in rat pituitary, with an upregulation of VEGF expression in estrogen-treated animals (10). Western blot analysis and RT-PCR of anterior pituitary tissues showed the presence of VEGF164 and VEGF120 (10). Jabbour et al (11) described that only scattered positive FS cells are present within the sheep pituitary. They identified $20 \%$ that were double-stained cells for VEGF and S-100; 80\% of cells that were stained only positive for VEGF, but were unidentified.

It is well known that extracellular matrix (ECM) plays an important role in studying cellular function in vitro. In the physiological environment, like ECM, cytokines and hormones, are absent under culture conditions of the pituitary cells. Laminine and type IV collagen are typical ECM constituents in both the epithelial and vascular basement membrane of the pituitary gland $(12,13)$. The ECM components are able to influence the morphological appearance, growth behavior and migratory activity of epithelial cells. Both, tumor and normal cells of epithelial origin (lactotrophs), are more likely to reflect their in vivo counterparts when maintained on ECM, instead of uncoated plastic (14). ECM components also influence pituitary function in vivo $(15,16)$.

The present study was designed to identify VEGF producing cells, other than FS cells, in the anterior pituitary gland of rats in vivo and in vitro and to investigate the influence of ECM (Matrigel) on VEGF production in primary pituitary cell cultures.

\section{Materials and methods}

Ethics statement. The present study was performed in accordance with the recommendations of the Guide for the Care and Use of Laboratory Animals of the National Institutes of Health. The protocol was approved by the local Ethics Committee for animal experiments of RWTH University of Aachen, School of Medicine (permit no. 1077 A4; 2001). All the experiments were performed without suffering of the animals.

Animals. Adult female Sprague Dawley rats of $250 \mathrm{~g}$ body weight were used, bred from a colony at the Institute for animal research (RWTH University of Aachen, Germany). Rats were housed in groups of four per cage in a quiet and light-regulated 
Table I. Antibodies.

\begin{tabular}{llll}
\hline Antibody & \multicolumn{1}{c}{ Antigen } & Dilution & \\
\hline $\begin{array}{l}\text { Monoclonal antibodies } \\
\text { S-100 }\end{array}$ & S-100 protein & $1: 100$ & Source \\
$\begin{array}{l}\text { Polyclonal antibodies } \\
\text { Prolactin (rabbit) }\end{array}$ & Prolactin & $1: 1000$ & Biotrend, Köln, Germany \\
VEGF (147) (rabbit) & VEGF & $1: 30$ & Santa Cruz Biotechnology, Heidelberg, Germany \\
S-100 (rabbit) & S-100 protein & $1: 300$ & Dako, Hamburg, Germany \\
Prolactin (M-19) (goat) & Prolactin & $1: 30$ & Santa Cruz Biotechnology, Heidelberg, Germany \\
\hline
\end{tabular}

room; the temperature was maintained at $20-21^{\circ} \mathrm{C}$. Food and water supply was available ad libitum. Experiments were started between 9-10 h to exclude changes associated with circadian rhythm. Vaginal swabs were taken at $8 \mathrm{~h}$, were alcohol fixed and stained (Papanicolaou). Rats at the estrous stage were sacrificed by cervical dislocation under anesthesia with Forene (Isofluran, Abbot). The pituitary was removed immediately and formalin-fixed for paraffin-embedding, deep-frozen or treated for cell-culture/cytospin-preparation as described later.

Materials. Cell culture materials and reagents were obtained from Greiner Labortechnik (Solingen, Germany), Falcon (Heidelberg, Germany), Seromed (Berlin, Germany) and Sigma (Deisenhofen, Germany). Matrigel was obtained from Becton-Dickinson (Heidelberg, Germany). A list of antibodies is given in Table $\mathrm{I}$.

Cell culture. Rat pituitary monolayer cell cultures were generated following a modified protocol (17). In brief, the pituitaries were washed 3 times and then cut into small pieces.

Cell dissociation was performed with trypsin-type III ( $25 \mathrm{mg} / 5 \mathrm{ml}$ medium) for $15 \mathrm{~min}$ at $37^{\circ} \mathrm{C}$. DNase type $\mathrm{V}$ solution (10 mg/5 ml medium) was added for $1 \mathrm{~min}$. After centrifugation at $500 \mathrm{~g}$ for $2 \mathrm{~min}$, supernatants were removed and cell pellets were incubated for 5 min with a trypsin inhibitor (type $\mathrm{I}-\mathrm{S}, 5 \mathrm{mg} / 5 \mathrm{ml}$ medium) and again centrifuged for $2 \mathrm{~min}$. The cells were then incubated in EDTA solution, $2 \times 5 \mathrm{~min}$ in $2 \mathrm{mM}$ EDTA and $2 \times 5 \mathrm{~min}$ in $1 \mathrm{mM}$ EDTA. The digested pieces of the pituitary were dispersed and cell viability was determined by trypan blue exclusion. After counting, the cells were seeded into 24-well plates (TPP tissue culture plates, Sigma) at a concentration of 300,000 cells/well. Cells were incubated at $37^{\circ} \mathrm{C}$ and $5 \% \mathrm{CO}_{2}$ in medium 199 with $2.2 \mathrm{~g} / 1 \mathrm{NaHCO}_{3}$ supplemented with $10 \%$ FCS (inactivated for $1 \mathrm{~h}$ at $56^{\circ} \mathrm{C}$ ), $2 \mathrm{mM}$ glutamine and penicillin/streptomycin $\left(10^{5} \mathrm{U} / 10^{5} \mu \mathrm{g} / \mathrm{ml}\right)$. After 2 days the medium was changed. On day 4 , monolayers were washed with PBS and serum-free culture medium was added for $24 \mathrm{~h}$ to dilute the serum. On day 5 serum free media were replaced for another 48-h incubation period.

Culture on Matrigel and plastic. Accordingly, cells were cultivated on Matrigel (Becton-Dickinson). Matrigel was diluted 1:1 with a serum-free medium. Culture plates were covered with Matrigel solutions and incubated for $1 \mathrm{~h}$ at $37^{\circ} \mathrm{C}$ for polymerization. Cells were seeded on top of the gel. Supernatants from Matrigel-coated wells as well as from plastic, were pooled (12-wells/culture), centrifuged and stored at $-20^{\circ} \mathrm{C}$ for $\mathrm{VEGF}$ quantification.

Immunohistochemistry. Immunohistochemistry was performed on formalin fixed (fixation with buffered formalin, pH 6.5-7.2) paraffin-embedded pituitary gland sections (4 $\mu \mathrm{m})$ and cryostat sections of resected pituitary glands $(6 \mu \mathrm{m})$. A streptavidin-biotin-peroxidase method was employed. Paraffin sections were deparaffinized and rehydrated in PBS. Cryosections were fixed in acetone $\left(4^{\circ} \mathrm{C}\right.$ for $\left.10 \mathrm{~min}\right)$. Cell cultures were fixed in methanol $\left(4^{\circ} \mathrm{C}\right.$ for $\left.10 \mathrm{~min}\right)$. Endogenous peroxidase activity was blocked with $0.3 \%$ hydrogen peroxide for $30 \mathrm{~min}$. Paraffin sections were incubated with trypsin (Dako, Hamburg, Germany) for $15 \mathrm{~min}$. For negative controls, phosphate-buffered saline (PBS; Dulbecco) diluent, without $\mathrm{Ca}^{2+}$ and $\mathrm{Mg}^{2+}$, containing $1.5 \%$ bovine serum albumin (BSA) replaced the primary antibody. In addition, rabbit immunoglobulin G (IgG; Dako), goat IgG (Dianova, Hamburg, Germany) and normal mouse IgG (Dianova) were used at the identical concentration as the primary antibody. Human endometrium of mid-luteal phase, from a patient of proven fertility, served as a positive control for VEGF staining. Endometrial tissue block was used with the informed consent of the participant patient (18).

Primary antibodies (Table I) were applied overnight at $4^{\circ} \mathrm{C}$ for paraffin embedded sections, whereas cryosections, cytospin-preparations of pituitary cell suspension (detection of lactotroph and FS cells) and cultured cells were incubated for $4 \mathrm{~h}$. We used the LSAB2-kit (kit for use on rat specimens, Dako) for primary mouse and rabbit antibodies. Visualization of specific antigens was performed by peroxidase-catalyzing substrate and converting with chromogene aminoethyl carbazole (AEC; Zymed Laboratories Inc., San Francisco, CA, USA) to a red-colored deposit.

Double staining of VEGF and prolactin. Staining was performed on 24-well culture plates. After removing culture media, cells were fixed with methanol $\left(4^{\circ} \mathrm{C}\right.$ for $\left.10 \mathrm{~min}\right)$, rehydrated with PBS and blocked with a donkey serum (dilution 1:20 in PBS), followed by an overnight incubation with prolactin antibodies (dilution 1:30 in $\mathrm{PBS} / 2 \%$ rat serum, Santa Cruz, CA, USA) at $4^{\circ} \mathrm{C}$. The secondary antibody (TRITC, donkey anti-goat, Dianova) was diluted 1:100 in PBS (pH 8.2) containing a $2 \%$ rat serum and was incubated for $30 \mathrm{~min}$. After three rinses with PBS, the cells were blocked with goat 
A

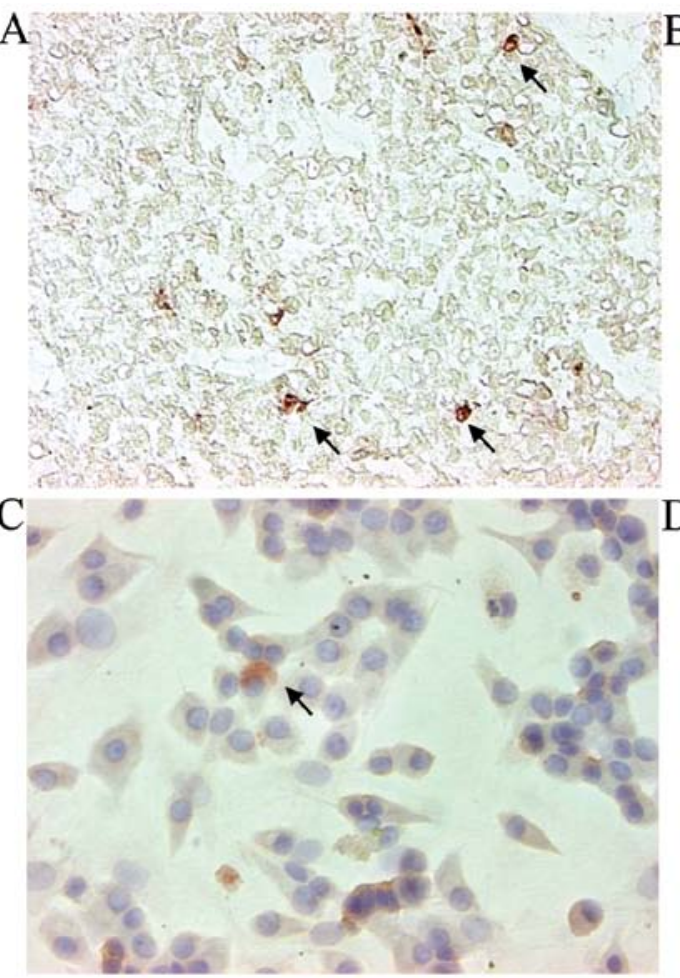

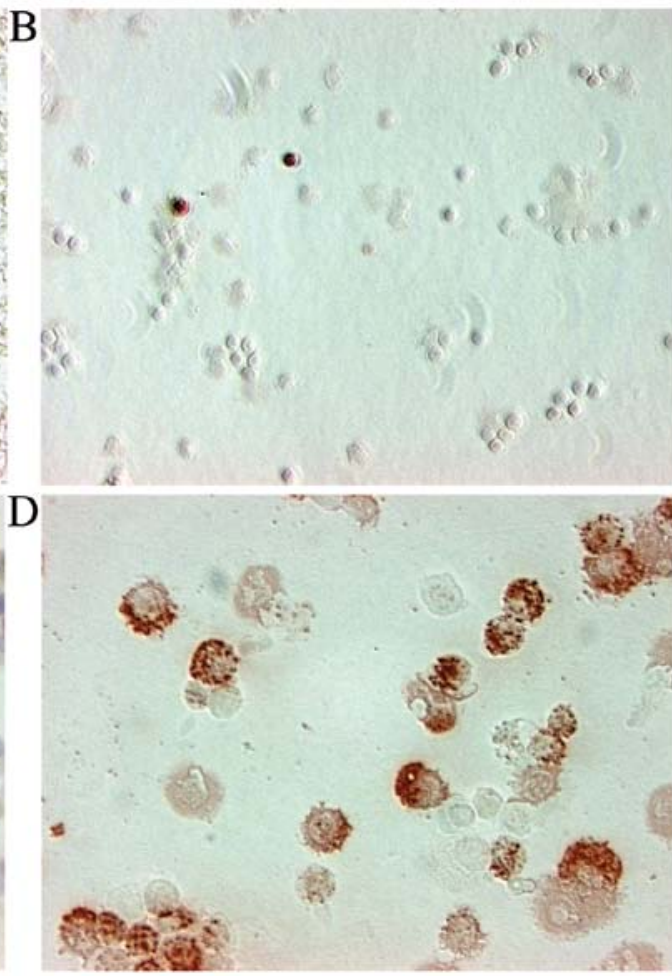

Figure. 1 (A-C) Folliculostellate cells in vivo and in vitro. (A) Cryostat section $(4 \mu \mathrm{m})$ of rat anterior pituitary gland by immunohistochemistry with S100 antibody. Scattered cells are stained as indicated by the black arrows. (B) Dispersed pituitary cells after treatment with collagenase before seeding into wells (cytospin-preparation). Only scattered cells are immunocytochemical positive for S-100 indicated by the black arrows. (C) Primary pituitary cells after 7 days of culture on plastic. A single S100 positive cell is detected as indicated by the black arrow. The cells are counterstained with hematoxylin. (D) Dispersed pituitary cells after treatment with collagenase before seeding into wells (cytospin-preparation). Nearly $50 \%$ of the cells are immunocytochemically positive for prolactin.

serum (dilution 1:20 in PBS, $10 \mathrm{~min}$ ), followed by incubation with an anti-VEGF-A antibody (dilution 1:30 in PBS/2\% rat serum, Santa Cruz) overnight at $4^{\circ} \mathrm{C}$. The secondary antibody (FITC, goat anti rabbit, Linaris) was diluted 1:50 in PBS ( $\mathrm{pH} 8.2+2 \%$ rat serum) for $30 \mathrm{~min}$. The cells were incubated with $\mathrm{KCl}(200 \mathrm{mmol})$ for $5 \mathrm{~min}$ and then with DAPI $(0.2 \mu \mathrm{g} / \mathrm{ml}$ PBS pH 7.0, Sigma) for $1 \mathrm{~h}$ and finally mounted with medium for fluorescence analysis (Vector Laboratories, Burlingame, CA, USA).

For negative controls phosphate-buffered saline (PBS, Dulbecco, w/o $\mathrm{Ca}^{++}$, w/o $\mathrm{Mg}^{++}$) containing $2 \%$ rat serum replaced the primary antibody. Rabbit IgG (Dako) and goat IgG (Dianova) were applied at equal concentrations as the primary antibody.

VEGF detection within culture medium. VEGF was quantified by ELISA (R\&D Systems, Wiesbaden-Nordenstadt, Germany; test validations according to the provider's specification), which is able to identify the VEGF-164 and VEGF-120 isoform of the mouse. Cross-reactivity ( $>95 \%$ ) to the corresponding rat VEGF enables the application of this ELISA. Protein detection is done by the Lowry-test.

Identification of FS. FS cells, identified by monoclonal and polyclonal antibodies against S-100 protein (Table I), were counted on cytospin-preparations of dispersed pituitary cells, after seven days of culture and on cryostat sections as well as on formalinfixed and paraffin-embedded sections of the pituitary gland.
Estimation of cell type distribution. For semi-quantification analysis of the different cell types 10 high-power fields were analyzed.

Statistical analysis. Experiments were repeated six times. The Mann-Whitney U test was used for statistics. Data are shown as means \pm standard deviation.

Illustrations were performed with Axiovert 135 microscope (Zeiss, Göttingen, Germany). We performed quadruple overlay of immunohistochemical analysis as follows: i) immunocytochemical detection of prolactin; ii) immunocytochemical detection of VEGF; iii) DAPI counterstaining; iv) light microscopic picture.

\section{Results}

FS in vivo and in vitro. FS cells are identified by two different antibodies against S-100 protein. Both antibodies, monoclonal (BioGenex, Hamburg, Germany) and polyclonal (Dako), showed similar results. S-100 positive FS cells are infrequently detected in cryostat (Fig. 1A) and paraffin sections (data not shown) of the anterior pituitary gland. Approximately $1.6 \%$ of the pituitary cells stain positive for S-100. We also performed a cytospin-preparation of dispersed pituitary cells (before seeding into culture wells) to identify S-100 positive cells by immunocytochemistry. Only few FS were identified (Fig. 1B), even after seven days of culture only the scattered stained cells were visible (2.4\% S-100 positive cells; Fig. 1C). 


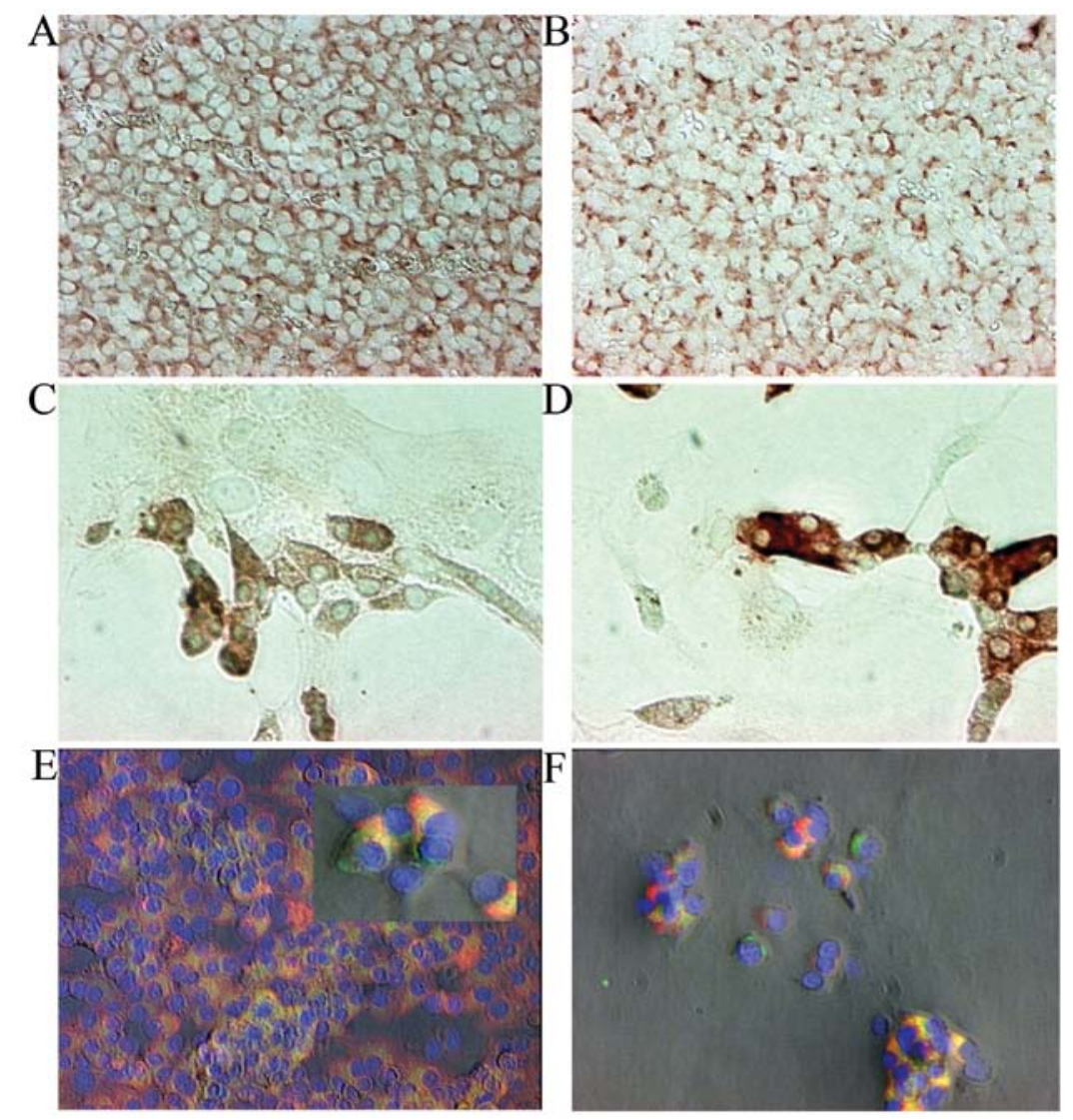

Figure. 2 Paraffin serial sections and cell cultures with immunostaining for VEGF and prolactin. (A) Paraffin section of anterior pituitary gland with an even signal for VEGF (red deposit, AEC). (B) Paraffin section with nearly identical signals for prolactin (red deposit, AEC), when compared with VEGF. (C and D) cultures of primary rat pituitary cells on plastic dishes after 7 days of culture demonstrate positive immunocytochemical signals for VEGF (C) and prolactin (D). (E and F) Cultures of primary rat pituitary cells on Matrigel (E) and plastic dishes (F) after 7 days of culture. (E) Double staining for prolactin (TRITC, red) and VEGF (FITC, green). Many cells stain for prolactin and VEGF (yellow). Negative and single stained cells are seen. The inset (E) demonstrates double and single stained cells. (F) Double staining for prolactin (TRITC, red colour) and VEGF (FITC, green). Many cells stain for prolactin and VEGF (yellow). VEGF, vascular endothelial growth factor.
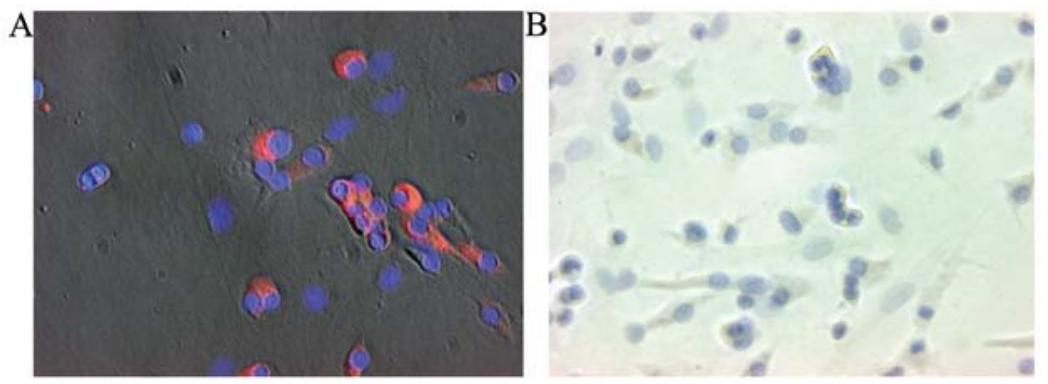

Figure 3. Negative controls. For negative controls phosphate-buffered saline (PBS; Dulbecco), without $\mathrm{Ca}^{2+}$ and $\mathrm{Mg}^{2+}$ containing $1.5 \%$ BSA, replaced the primary antibody. In addition, rabbit immunoglobulin $\mathrm{G}$ (IgG; Dako) and goat $\operatorname{IgG}$ (Dianova) were used at the identical concentration as the primary antibody. (A) Double immunohistochemistry with rabbit IgG replacing VEGF antibody. Prolactin positive cells are red (TRITC). There is no green signal for VEGF. (B) Goat IgG replacing prolactin antibody. The cells are negative. Negative controls with rabbit or mouse IgG are also negative (data not shown). VEGF, vascular endothelial growth factor; BSA, bovine serum albumin.

VEGF and prolactin in vivo and in vitro. Results demonstrate a uniform and nearly identical staining pattern for VEGF and prolactin on paraffin serial sections of pituitary cells (Fig. 2A and B). Detection of lactotroph cells on cytospin-preparations was performed in pituitary cell culture (Fig. 1D). Approximately 50\% of the cells stained were positive for prolactin. After seven days of culture, the cells with small nuclei (functional pituitary cells) were positive for VEGF, as well as for prolactin (Fig. 2C and D). Cells with large nuclei (fibroblasts, positive for vimentin, data not shown) were negative for VEGF and prolactin. The staining demonstrate that groups of cells are positive for both prolactin and VEGF (Fig. 2E on Matrigel and F on plastic). Few cells were stained only for VEGF. Nearly $21 \%$ of the cells were completely negative for both proteins. The staining pattern of cells cultured on plastic, did not differ from those cultured on Matrigel, although the staining intensity for VEGF was appreciably less in the cells cultured on ECM. Negative control 


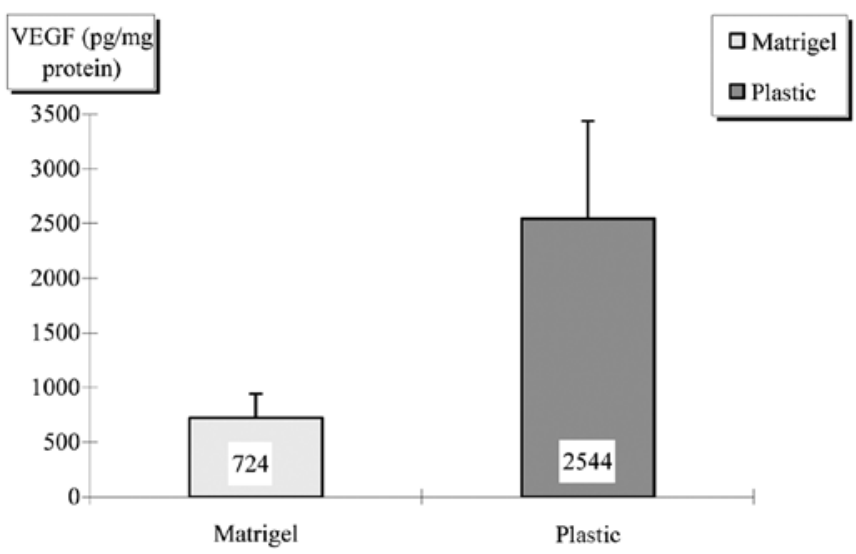

Figure 4. Results of ELISA from culture supernatants. Release of VEGF ( $\mathrm{pg} / \mathrm{mg}$ protein) from primary rat pituitary cells after a $48 \mathrm{~h}$ incubation period. ECM [Matrigel-coated wells demonstrate significantly lower VEGF production than uncoated wells $(\mathrm{P}<0.0022)]$. Values are means \pm standard deviation. VEGF, vascular endothelial growth factor; ECM, extracellular matrix.

with rabbit IgG, replacing the VEGF antibody in immunocytochemistry with prolactin antibody (Fig. 3A), resulted in a positive signal for prolactin whereas rabbit IgG was negative; the negative control with goat IgG (replacing the prolactin antibody, Fig. 3B) resulted in no visual signal. A biopsy of the human endometrium (mid luteal phase) served as a positive control for VEGF-A (18).

VEGF production in primary rat pituitary cell culture. ELISA results reveal less statistically significant VEGF production $(\mathrm{P}<0.0022)$ of cells cultured on Matrigel $(724 \pm 243 \mathrm{pg} / \mathrm{mg}$ VEGF, means \pm SD vs. cells grown on uncoated plastic wells (2544 $\pm 951 \mathrm{pg} / \mathrm{mg}$ VEGF, means \pm SD) (Fig. 4).

\section{Discussion}

This study demonstrates for the first time, since the identification of VEGF in FS (1) that lactotrophs are the main source of VEGF production in the normal pituitary gland.

Jabbour et al (11) identified scattered positive FS cells within the sheep pituitary. Approximately $80 \%$ of non-FS cells were stained positive for VEGF and remained unidentified. Lactotrophs apparently are the main source of VEGF-production in the pituitary gland and represent a significant portion of the unidentified population.

Here, we demonstrate that FS cells are only infrequently present in vivo (1.6\%, paraffin section of rat pituitary), after dispersing cells in cell culture (cytospin-preparation) and in vitro (2.4\%), as identified by two different antibodies against S-100 protein. Our results differ from the data of Vankelecom et al (4), where they identified $7.5 \%$ FS cells in mouse pituitary using another antibody against the $S-100$ protein. This can be explained by the fact that the quantity of pituitary FS cells varies between different rat strains such as Fischer 344 and Sprague Dawley rats used in this study. It has been described that Fischer 344 rats have significantly more FS cells (19). Based on studies, that estrogen-induced prolactin secreting tumors in the F344 rat are associated with upregulation of VEGF, it was suggested that lactotrophs may be responsible for VEGF production (20). Our immunohistological detection of widespread VEGF protein signals on cryostat as well as paraffin sections of the anterior pituitary gland confirm the results of Ochoa et al (10). They detected a uniform expression VEGF mRNA by in situ hybridization throughout the anterior lobe of the rat pituitary gland. This uniform mRNA expression indicates that not only scattered FS cells were responsible for the VEGF mRNA production. It was speculated that lactotrophs and FS cells, which together comprise $50-60 \%$ of all pituitary cells (21), may be involved in the VEGF secretion. Our investigations show that lactotrophs are the main source of VEGF production under physiological conditions.

Since curcumin suppresses VEGF release in pituitary adenomas, it has been suspected that it may inhibit pituitary adenoma progression not only through anti-proliferative and pro-apoptotic actions, but also by suppressing pituitary tumor neovascularization (22). Our results strongly support the notion that curcumin has an important impact on lactotrophs and their VEGF production. It is also notable that estradiol stimulates VEGF and interleukin-6 in human lactotroph and lactosomatotroph pituitary adenomas (23). Estrogen administration enhances the expression of proangiogenic factors (e.g., VEGF) in pituitary grafts (24). Indeed, prolactinomas show higher VEGF protein expression compared to nonfunctioning or ACTH- and GH-secreting adenomas (25). The overexpression of vascular endothelial growth factor in pituitary adenomas is associated with extracellular growth and recurrence. Therefore VEGF and its receptors (VEGFR's) may play an important clinical role in targeted tumor therapy of pituitary tumors (26).

Results of in vivo studies cannot exclude the involvement of contributing factors, i.e., cells or ECM molecules. In vitro studies performed to examine the effects of VEGF on endothelial cells show that VEGF in the presence of a basal lamina-type ECM specifically induces fenestrations in endothelial cells (27). Other data suggest that Matrigel is necessary to prevent biased functions of cells in culture. It is well documented that epithelial cells dedifferentiate in vitro when cultured on plastic (28). Our results demonstrate that lactotrophs are positive for pan-cytokeratin (data not shown), which is typical for epithelial cells, implying that these cells also need ECM for adequate function. With quantification of VEGF in the culture medium by ELISA, it was apparent that Matrigel inhibits VEGF secretion from pituitary cells in culture. As demonstrated by several authors, ECM supports pituitary cell function. Matrigel reduces proliferation and increases prolactin expression of GH3 cells (29). Pituitary cells cultured on plastic produce elevated amounts of VEGF, which is explained by the increased cellular stress that is induced by the artificial plastic surface. Consequently, the cell culture of lactotrophs on ECM better reflects the physiologic conditions compared to uncoated plastic due to disturbed cell function.

In the present study, we demonstrated for the first time, that lactotrophs, which represent $\sim 50 \%$ of the anterior pituitary gland cells, are the major source of VEGF production in vitro as in vivo. This is important for the interpretation of antiangiogenic treatment and therapeutic response of pituitary tumors treated with anti-VEGF therapy.

ECM is able to influence VEGF release in primary cell culture. We conclude that in vitro studies with cell lines and 
primary cell cultures should be performed on ECM to avoid false results.

\section{Acknowledgements}

The present study was supported by a grant $(5-2,000)$ of the medical faculty (RWTH Aachen). We would like to thank Professor Edward Geissler for the critical review of the manuscript.

\section{References}

1. Ferrara N and Henzel WJ: Pituitary follicular cells secrete a novel heparin-binding growth factor specific for vascular endothelial cells. Biochem Biophys Res Commun 161: 851-858, 1989.

2. Leung DW, Cachianes G, Kuang WJ, Goeddel DV and Ferrara N: Vascular endothelial growth factor is a secreted angiogenic mitogen. Science 246: 1306-1309, 1989.

3. Nakajima T, Yamaguchi H and Takahashi K: S100 protein in folliculostellate cells of the rat pituitary anterior lobe. Brain Res 191: 523-531, 1980.

4. Vankelecom H, Matthys P, Van Damme J, Heremans H, Billiau A and Denef C: Immunocytochemical evidence that S-100-positive cells of the mouse anterior pituitary contain interleukin-6 immunoreactivity. J Histochem Cytochem 41: 151-156, 1993.

5. Gracia-Navarro F, Porter D, Garcia-Navarro S and Licht P: Immunocy tochemical and ultrastructural study of the frog (Rana pipiens) pars distalis with special reference to folliculo-stellate cell function during in vitro superfusion. Cell Tissue Res 256 623-630, 1989.

6. Amano O, Yoshitake Y, Nishikawa $\mathrm{K}$ and Iseki S: Immunocytochemical localization of basic fibroblast growth factor in the rat pituitary gland. Arch Histol Cytol 56: 269-276, 1993.

7. Hentges S, Boyadjieva N and Sarkar DK: Transforming growth factor-beta3 stimulates lactotrope cell growth by increasing basic fibroblast growth factor from folliculo-stellate cells. Endocrinology 141: 859-867, 2000.

8. Vankelecom H, Carmeliet P, Van Damme J, Billiau A and Denef C: Production of interleukin- 6 by folliculo-stellate cells of the anterior pituitary gland in a histiotypic cell aggregate culture system. Neuroendocrinology 49: 102-106, 1989.

9. Horvath E and Kovacs K: Folliculo-stellate cells of the human pituitary: A type of adult stem cell? Ultrastruct Pathol 26: 219-228, 2002.

10. Ochoa AL, Mitchner NA, Paynter CD, Morris RE and Ben-Jonathan N: Vascular endothelial growth factor in the rat pituitary: differential distribution and regulation by estrogen. $\mathrm{J}$ Endocrinol 165: 483-492, 2000.

11. Jabbour HN, Boddy SC and Lincoln GA: Pattern and localisation of expression of vascular endothelial growth factor and its receptor flt- 1 in the ovine pituitary gland: expression is independent of hypothalamic control. Mol Cell Endocrinol 134: 91-100, 1997.

12. Vila-Porcile E, Picart R, Vigny M, Tixier-Vidal A and Tougard C: Immunolocalization of laminin, heparan-sulfate proteoglycan, entactin, and type IV collagen in the rat anterior pituitary. I. An in vivo study. Anat Rec 232: 482-492, 1992.
13. Murray K, de Lera JM, Astudillo A and McNicol AM: Organisation of basement membrane components in the human adult and fetal pituitary gland and in pituitary adenomas. Virchows Arch 431: 329-335, 1997.

14. Vlodavsky I, Lui GM and Gospodarowicz D: Morphological appearance, growth behavior and migratory activity of human tumor cells maintained on extracellular matrix versus plastic. Cell 19: 607-616, 1980.

15. Bethea CL and Weiner RI: Human prolactin secreting adenoma cells maintained on extracellular matrix. Endocrinology 108: 357-360, 1981.

16. Horacek MJ, Dada MO and Terracio L: Reconstituted basement membrane influences prolactin, $\mathrm{LH}$, and FSH secretion from adult and fetal adenohypophyseal cells in vitro. J Cell Physiol 151: 180-189, 1992.

17. Kiesel L and Catt KJ: Phosphatidic acid and the calcium-dependent actions of gonadotropin-releasing hormone in pituitary gonadotrophs. Arch Biochem Biophys 231: 202-210, 1984.

18. Classen-Linke I, Alfer J, Krusche CA, Chwalisz K, Rath W and Beier HM: Progestins, progesterone receptor modulators, and progesterone antagonists change VEGF release of endometrial cells in culture. Steroids 65: 763-771, 2000.

19. Oomizu S, Chaturvedi K and Sarkar DK: Folliculostellate cells determine the susceptibility of lactotropes to estradiol's mitogenic action. Endocrinology 145: 1473-1480, 2004.

20. Banerjee SK, Sarkar DK, Weston AP, De A and Campbell DR: Over expression of vascular endothelial growth factor and its receptor during the development of estrogen-induced rat pituitary tumors may mediate estrogen-initiated tumor angiogenesis. Carcinogenesis 18: 1155-1161, 1997.

21. Chen HT: Postnatal development of pituitary lactotropes in the rat measured by reverse hemolytic plaque assay. Endocrinology 120: 247-253, 1987.

22. Shan B, Schaaf C, Schmidt A, et al: Curcumin suppresses HIF1A synthesis and VEGFA release in pituitary adenomas. J Endocrinol 214: 389-398, 2012.

23. Onofri C, Carbia Nagashima A, Schaaf L, et al: Estradiol stimulates vascular endothelial growth factor and interleukin- 6 in human lactotroph and lactosomatotroph pituitary adenomas. Exp Clin Endocrinol Diabetes 112: 18-23, 2004.

24. Lombardero M, Quintanar-Stephano A, Vidal S, et al: Effect of estrogen on the blood supply of pituitary autografts in rats. J Anat 214: 235-244, 2009.

25. Cristina C, Perez-Millan MI, Luque G, et al: VEGF and CD31 association in pituitary adenomas. Endocr Pathol 21: 154-160, 2010.

26. Sánchez-Ortiga R, Sánchez-Tejada L, Moreno-Perez O, Riesgo P, Niveiro M and Picó Alfonso AM: Over-expression of vascular endothelial growth factor in pituitary adenomas is associated with extrasellar growth and recurrence. Pituitary 16: 370-377, 2013.

27. Esser S, Wolburg K, Wolburg H, Breier G, Kurzchalia T and Risau W: Vascular endothelial growth factor induces endothelial fenestrations in vitro. J Cell Biol 140: 947-959, 1998.

28. Schatz F, Gordon RE, Laufer N and Gurpide E: Culture of human endometrial cells under polarizing conditions. Differentiation 42: 184-190, 1990.

29. Lee BL, Yoo MJ, Kim WH, Hwang DH, Lee SK and Kleinman HK: Reconstituted basement membrane reduces proliferation and increases prolactin expression of GH3 cells. Endocr J 46: 597-604, 1999. 